\title{
Generalized Pustular Psoriasis Triggered by ChAdOx1nCoV-19 Vaccine: a case report
}

Livia Maria Salviano ${ }^{1}$, Bruno Breda ${ }^{1}$, Ricardo Romiti ${ }^{1}$, André Hirayama ${ }^{1}$, and Marcelo Arnone $^{1}$

${ }^{1}$ University of Sao Paulo Hospital of Clinics

February 22, 2022

Title:

Generalized Pustular Psoriasis Triggered by ChAdOx1nCoV-19 Vaccine: a case report

Authors:

Salviano LMO

Breda BJ

Romiti R (MD, PhD)

Hirayama ALS (MD)

Arnone M (MD)

Institution:

Department of Dermatology, Hospital das Clínicas, University of São Paulo, São Paulo (SP), Brazil

Address of Institution:

Av. Dr Eneas Carvalho de Aguiar, 255, Cerqueira Cesar,São Paulo, SP, Brazil; Post code: 0540300

Corresponding author

Livia Maria Oliveira Salviano

postal address: Rua Oscar Freire, 1523, apartment 1523, Pinheiros, São Paulo, Brazil; Post code: 05409010

E-mail: liviasalviano@gmail.com

Telephone number: +5562982518945

\section{Count:}

Manuscript: 474 words

Tables: 2

Conflict of interest

Livia Maria Oliveira Salviano has no conflict of interest.

Bruno Jose Breda has no conflict of interest. 
Ricardo Romiti , MD, $\mathrm{PhD}$, is/has served as a scientific consultant, speaker, or clinical study investigator for AbbVie, Boehringer Ingelheim, Galderma, Janssen-Cilag, Eli-Lilly, Leo-Pharma, Novartis, Pfizer, TEVA, and UCB

Andre Hirayama, MD, is/has served as scientific consultant, speaker, or clinical study investigator for Abbvie, Boeheringer-Ingelheim,Janssen, Lilly, Pharma Novartis, Pfizer and Roche

Marcelo Arnone, MD, is/has served as scientific consultant, speaker, or clinical study investigator for Abbvie, Boeheringer-Ingelheim, Glenmark, Janssen, Lilly, Leo-Pharma Novartis, Pfizer and UCB Biopharma

\section{Short running title:}

Pustular Psoriasis after ChAdOx1nCoV-19

\section{Introduction}

Psoriasis is an immune-mediated inflammatory disorder whose pathophysiology shares genetic and environmental factors promoting dysregulation of cytokines and $\mathrm{T}$ cell-mediated response. Some factors are well-established triggers, such as medications, infections and emotional stress. Vaccination is an unusual trigger, but the association between vaccination and onset/flares of psoriasis has been described. In the specific context of generalized pustular psoriasis (GPP), few case reports describing pustular outbreaks following vaccination have been reported and only two, including this case, described flares after COVID19vaccination $^{1-4}$, specifically Sinovac and $\mathrm{ChAdOx} 1 \mathrm{nCoV}-19$ vaccines. In addition, there is description of plaque psoriasis flare after COVID-19-Pfizer-BioNTechBNT16B2b2mRNA and ChAdOx1nCoV-19 vaccines ${ }^{5-7}$. To date, no case reports have been published describing the exacerbation of pustular psoriasis after vaccination with ChAdOx1nCoV-19.

\section{Case Report}

A 58-year-old Brazilian woman was admitted two weeks after an outbreak of generalized pustular lesions and systemic symptoms initiating three days after the first dose of ChAdOx1nCoV-19 vaccine. Clinical examination revealed generalized pustules on ill-defined areas of erythema and edema affecting the trunk, upper and lower limbs and systemic symptoms including malaise, nausea and asthenia.

The history of the patient included a diagnosis of plaque psoriasis at the age of 36 and two previous episodes of GPP: the first occurred during the third trimester of pregnancy (2001), which was treated with topical and systemic steroids; the second (2004) occurred after a respiratory infection while she was under treatment with $20 \mathrm{mg}$ /week of oral methotrexate. Acitretin $30 \mathrm{mg} /$ day was started with rapid control of pustular lesions but only partial control of her plaque psoriasis after two years of treatment. In October 2019, Ustequinumab 45mg was started with almost complete control. In April 2020, she presented COVID19 infection confirmed by RT-PCR, without exacerbation. In May 2021, three days after the first dose of the ChAdOx1nCoV-19 vaccine, a new episode of GPP initiated. Recent infection or drug use were ruled out. She was managed with the regular dose of Ustequinumab 45mg at the same day of admission and evolved with complete regression of pustular lesions and systemic symptoms 7 days later. No recurrences were observed during the next two months of follow-up, even after the second dose at July 2021.

\section{Discussion}

Until now, psoriasis flares have been reported after Bacillus Calmette-Guerin (BGC), tetanus diphtheria, pneumococcal polysaccharide, hepatitis B, influenza and more recently after the COVID19 vaccines. The main clinical manifestations are guttate and guttate-plaque variants ${ }^{2,3}$. GPP outbreaks following influenza, hepatitis B vaccination and intravesical BCG immunotherapy have been reported ${ }^{8-13}$ (Table 1). Flares after COVID19 vaccination have included one case after COVID-19-Pfizer-BioNTechBNT16B2b2mRNA and two cases after ChAdOx1nCoV-19 vaccine (plaque lesions) and one case after Sinovac vaccines (GPP) $)^{5-7}$. Our patient is the first report of a pustular outbreak following the ChAdOx1nCoV-19 vaccine (Table 2). 
Considering the COVID19 pandemic, the expansion of immunization and different vaccines, it is important to monitor these as potential triggers for flares or new-onset of psoriasis.

\section{References}

1. Mungui-Calzada P, Drake-Monfort M, Armesto S, Reguero-del Cura L, Lopez-Sundh AE, GonzalezLopez M. Psoriasis flare after influenza vaccination in Covid-19 era: a report of four cases from a single Centre.DermatolTher. 2020.

2. Sbidian E, Eftekahri P, Viguier M, et al. National survey of psoriasis flares after 2009 monovalent H1N1/seasonal vaccines. Dermatology. 2014;229(2):130-135

3. Gunes AT, Fetil E, Akarsu S, Ozbagcivan O, Babayeva L. Possible triggering effect of influenza vaccination on psoriasis. J Immunol Res. 2015;2015:258430

4. Raaschou-Nielsen W. Psoriasis vaccinalis; report of two cases, one following B.C.G. vaccination and one following vaccination against influenza.Acta Derm Venereol.1955;35(1):37-42.

5. Onsun N, Kaya G, Işık BG, Güneş B. A generalized pustular psoriasis flare after CoronaVac COVID-19 vaccination: Case report. Health Promotion Perspectives, 2021;11(2):261-262

6. Krajewski PK, Matusiak E, Szepietowski JC. Psoriasis flare up associated with second dose of PfizerBioNTech BNT16B2b2 COVID-19 mRNA vaccine. J EurAcadDermatolVenereol. 2021

7. Nagrani P, Jindal R, Goyal D. Onset/flare of psoriasis following the ChAdOx1 nCoV- 19 Corona Virus Vaccine (Oxford-AstraZeneca/Covishield): Report of two cases. Dermatol Ther. 2021

8. Macias VC, Cunha D. Psoriasis triggered by tetanus diphtheria vaccination. CutanOculToxicol. 2013;32(2):164-165

9. Yoneyama S, Kamiya K, Kishimoto M, Komine M, Ohtsuki M. Generalized exacerbation of psoriasis vulgaris induced by pneumococcal polysaccharide vaccine. J Dermatol. 2019;46(11):442-443

10. LauBW, LimDZ, CaponF, BarkerJN,ChoonSE.Juvenile generalized pustular psoriasis isa chronic recalcitrant disease: an analysis of 27 patients seen in a tertiary hospital in Johor, Malaysia.International Journal of Dermatology, 2017; 56(4): 392-399.

11. Doğan S, Yalçın B, Yılmaz E, Erden O. Pustular Activation of Plaque Psoriasis İnduced After Hepatitis B Vaccination.Turk J Dermatol 2019;13:46-8

12. Blum A, Suleiman S, Shalabi R (2013) Erythrodermic Pustular Psoriasis Triggered by Subcutaneous Flu Vaccine. J Clin Case Rep 3: 255.

13. Wee, J.S., Natkunarajah, J., Moosa, Y. and Marsden, R.A. (2012), Erythrodermic pustular psoriasis triggered by intravesical bacillus Calmette-Guérin immunotherapy. Clinical and Experimental Dermatology, 37: 455-457.

Table 1: GPP flares after vaccination (excluding COVID19 vaccines)

\begin{tabular}{llll}
\hline Vaccine & Influenza $^{12}$ & Hepatitis B & Intravesi \\
\hline Age & 59 & 26 & 80 \\
Sex & male & female & male \\
Days after vaccination & 2 & 10 & 42 \\
Regression & Almost complete (after systemic steroids) & Complete (after topical corticosteroids) & Complete \\
\hline
\end{tabular}

Table 2: Psoriasis flares after COVID19 vaccination

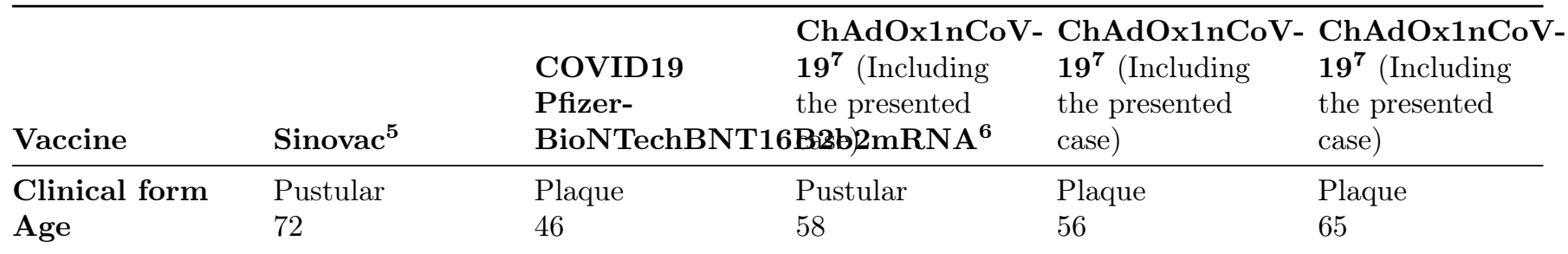




\begin{tabular}{|c|c|c|c|c|c|}
\hline Vaccine & Sinovac $^{5}$ & $\begin{array}{l}\text { COVID19 } \\
\text { Pfizer- } \\
\text { BioNTechBNT16 }\end{array}$ & $\begin{array}{l}\text { ChAdOx1nCoV- } \\
\mathbf{1 9}^{\mathbf{7}} \text { (Including } \\
\text { the presented } \\
\mathbf{6 B 2 b}) 2 \mathbf{m R N A}^{6}\end{array}$ & $\begin{array}{l}\text { ChAdOx1nCoV- } \\
\mathbf{1 9}^{\mathbf{7}} \text { (Including } \\
\text { the presented } \\
\text { case) }\end{array}$ & $\begin{array}{l}\text { ChAdOx1nCoV- } \\
\mathbf{1 9}^{\mathbf{7}} \text { (Including } \\
\text { the presented } \\
\text { case) }\end{array}$ \\
\hline Sex & male & male & female & female & female \\
\hline $\begin{array}{l}\text { Days after } \\
\text { vaccination }\end{array}$ & 4 & 1 & 3 & $\begin{array}{l}7\left(1^{\mathrm{a}} \text { dose }\right) 2\left(2^{\mathrm{a}}\right. \\
\text { dose })\end{array}$ & 10 \\
\hline Regression & $\begin{array}{l}\text { Complete (after } \\
\text { infliximab) }\end{array}$ & - & $\begin{array}{l}\text { Complete (after } \\
\text { Ustequinumabe) }\end{array}$ & $\begin{array}{l}\text { Partial (after } \\
\text { Apremilast/emollien }\end{array}$ & $\begin{array}{l}\text { Partial (after } \\
\text { enAspremilast/emollients) }\end{array}$ \\
\hline $\begin{array}{l}\text { Previous } \\
\text { Covid19 } \\
\text { infection }\end{array}$ & No & - & Yes & - & - \\
\hline
\end{tabular}

